802018

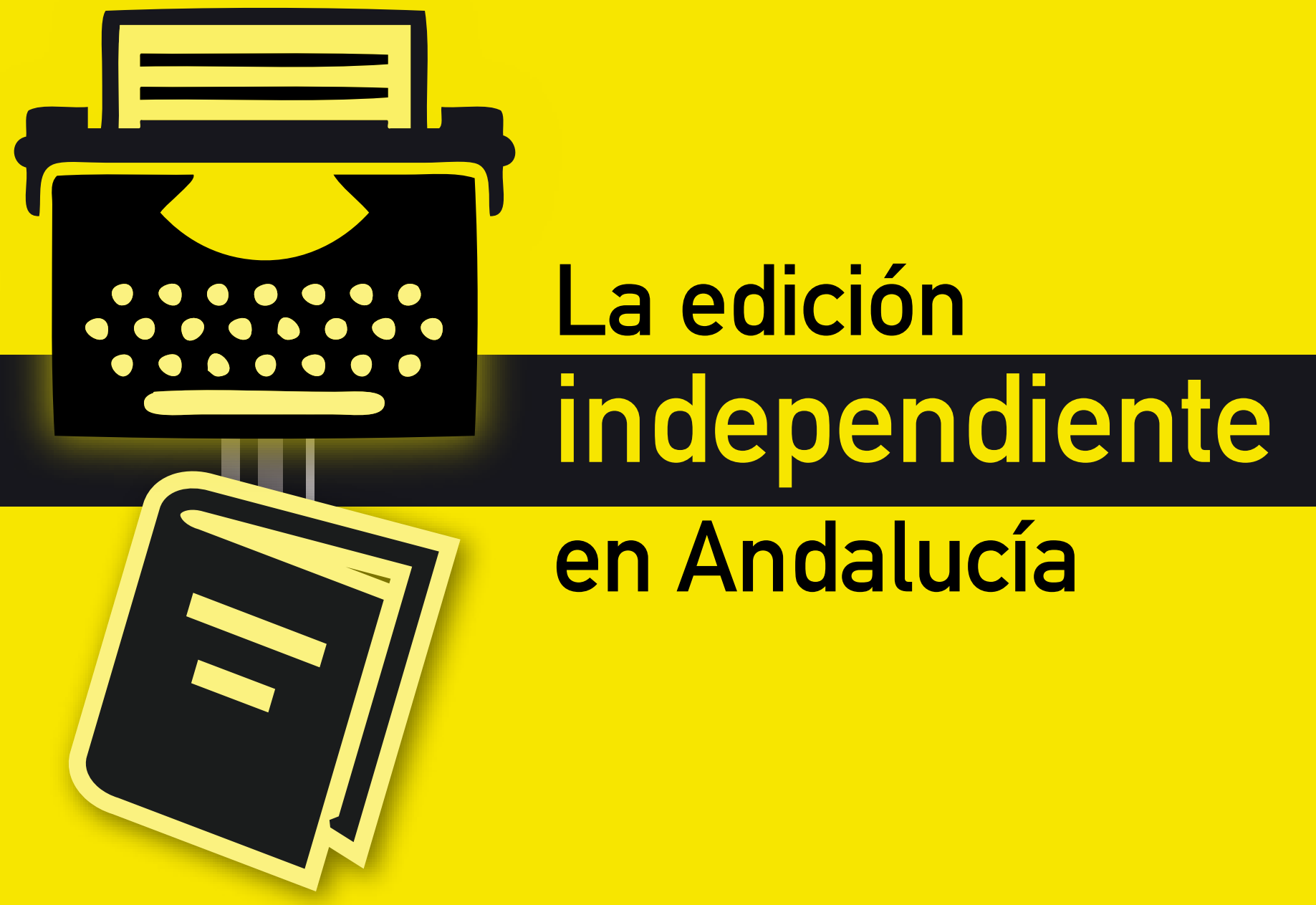




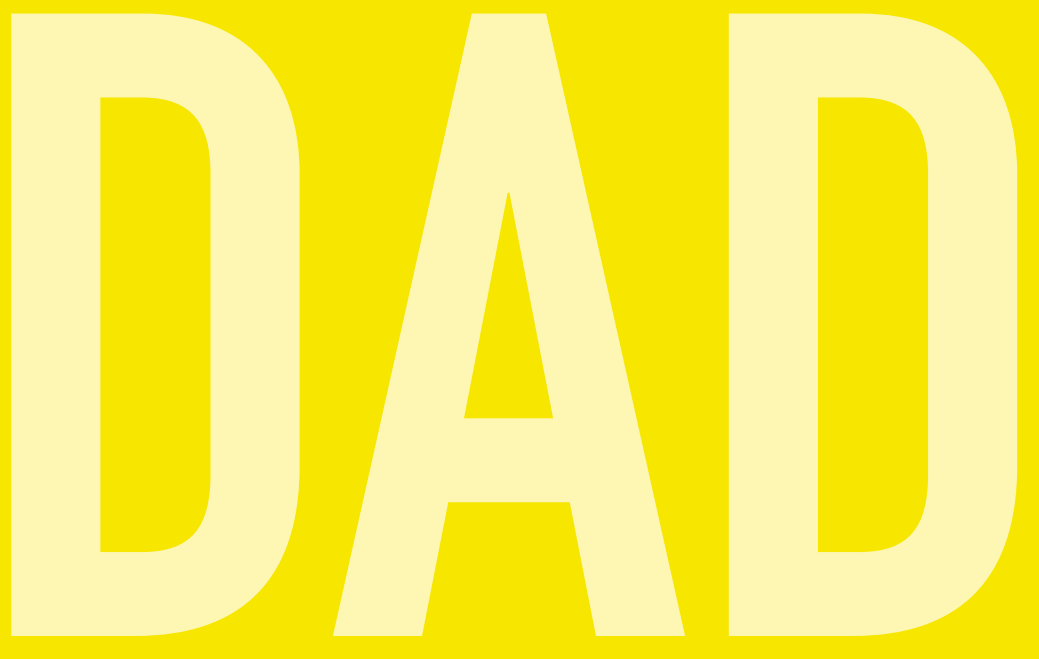


LA FUNDACIÓN CENTRO DE ESTUDIOS ANDALUCES ES UNA ENTIDAD DE CARÁCTER CIENTÍFICO Y CULTURAL, SIN ÁNIMO DE LUCRO, ADSCRITA A LA CONSEJERÍA DE LA PRESIDENCIA, ADMINISTRACIÓN LOCAL Y MEMORIA DEMOCRÁTICA DE LA JUNTA DE ANDALUCIIA. ENTRE NUESTROS OBJETIVOS FUNDACIONALES SE ESTABLECEN EL FOMENTO DE LA INVESTIGACIÓN CIENTÍFICA, LA GENERACIÓN DE CONOCIMIENTO SOBRE LA REALIDAD SOCIAL, ECONÓMICA Y CULTURAL DE ANDALUCÍA Y LA DIFUSIÓN DE SUS RESULTADOS EN BENEFICIO DE TODA LA SOCIEDAD.

NUESTRO COMPROMISO CON EL PROGRESO DE ANDALUCÍA NOS IMPULSA A LA CREACIÓN DE ESPACIOS DE INTERCAMBIO DE CONOCIMIENTO CON LA COMUNIDAD CIENTÍFICA E INTELECTUAL Y CON LA CIUDADANÍA EN GENERAL, Y A LA COLABORACIÓN ACTIVA CON LAS INSTITUCIONES PÚBLICAS Y PRIVADAS QUE INFLUYEN EN EL DESARROLLO DE LA COMUNIDAD AUTÓNOMA.

LA COLECCIÓN ACTUALIDAD FORMA PARTE DEL CATÁLOGO DE PUBLICACIONES CIENTÍFICAS DE LA FUNDACIÓN Y ESTÁ DESTINADA TANTO AL LECTOR ESPECIALIZADO COMO A LA OPINIÓN PÚBLICA EN GENERAL. CADA UNA DE SUS EDICIONES SE ESTRUCTURA COMO INFORMES MONOGRÁFICOS PARA EL FOMENTO DE LA REFLEXIÓN Y EL ANÁLISIS SOBRE ASPECTOS DE RELEVANCIA PARA LA SOCIEDAD ANDALUZA DEL SIGLO XXI.

LAS OPINIONES PUBLICADAS POR LOS AUTORES EN ESTA COLECCIÓN SON DE SU EXCLUSIVA RESPONSABILIDAD.

(C) Del texto: sus autores, 2018

(C) De la edición: Fundación Pública Andaluza

Centro de Estudios Andaluces, octubre de 2018

Bailén 50, 41001 Sevilla.

Tel.: 955055 210. Fax: 955055211

www.centrodeestudiosandaluces.es

Depósito Legal: SE-1688-05

I.S.S.N.: 1699-8294

Ejemplar Gratuito. Prohibida su venta. 



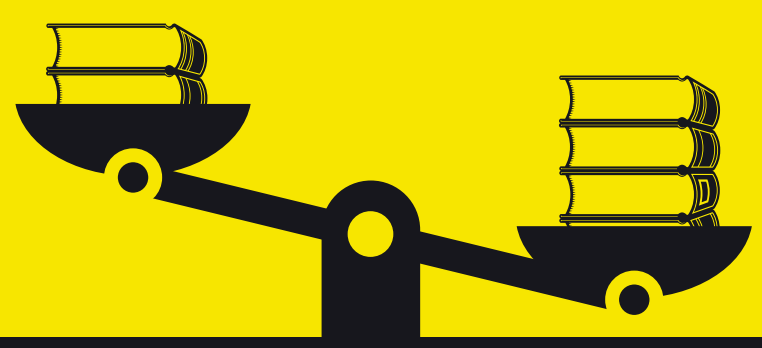

\section{La edición independiente en Andalucía}

Investigadora Principal

ANA GALLEGO CUIÑAS

Universidad de Granada

Equipo de investigación

ERIKA MARTíNEZ CABRERA

VIRGINIA CAPOTE DÍAZ

Colaboradora

MARÍA JOSÉ OTEROS TAPIA

Este documento es fruto del proyecto I+D EDITANDA, Patrimonio literario y mercado editorial en Andalucia: proyecciones transatlánticas (PRY151/14), financiado en la IX Convocatoria de Proyectos de Investigación de la Fundación Pública Andaluza Centro de Estudios Andaluces. 


\section{ÍNDICE}

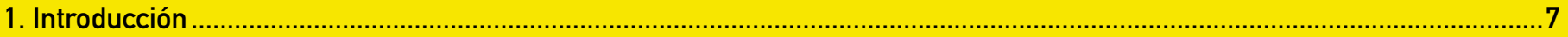

2. Criterios de selección y metodología: ¿qué es ser una editorial independiente en Andalucía?.............................................8

2.1. Hacia una cartografía de la edición independiente en Andalucía...........................................................................11

3. En los márgenes de la edición independiente: ser mujer y ser andaluz .......................................................................15

3.1. Presencia de escritoras en los catálogos de las editoriales independientes de Andalucía .............................................16

3.2. Presencia de escritores andaluces en los catálogos de editoriales independientes de Andalucía .................................16

4. Perfil económico de las editoriales independientes andaluzas .......................................................................................

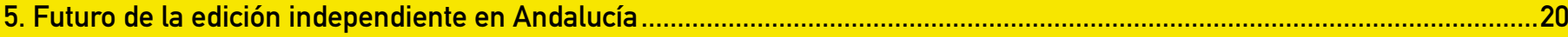

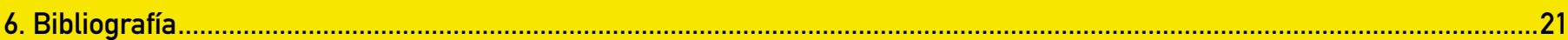




\section{Introducción}

«Frente a las lógicas financieras, cada vez más editores independientes reaccionan, multiplican las estrategias de resistencia y contribuyen al mantenimiento de una edición plural, comprometida, apasionante, capaz de proponer a los lectores los mil sabores del mundo, la infinitud de las ideas de los pueblos, la diversidad de las culturas».

Gilles Colleu

El sector editorial en Andalucía ha recibido un notable impulso en los últimos años como consecuencia de la crisis económica que ha afectado a los grandes conglomerados y que, por el contrario, ha favorecido la aparición de pequeñas editoriales llamadas «independientes» como modelo de negocio sostenible. Muchos de estos sellos nacen para cubrir parcelas de mercado que quedan descubiertas por las grandes empresas, como el lanzamiento de autores noveles y estéticas vanguardistas, obras descatalogadas, géneros menores, traducciones de lenguas no centrales, etc., que les permite no solo sobrevivir en el mercado del libro sino contribuir al equilibrio de su ecosistema y a la bibliodiversidad. A esto hay que añadir las nuevas condiciones materiales de la publicación del objeto libro, los modos de producción y circulación editoriales, que se han abaratado sobremanera por las nuevas tecnologías y las redes sociales. Todo ello ha propiciado el desarrollo del fenómeno de la edición independiente en el siglo xxı, un fenómeno que habría de ser analizado en su conjunto y variedad desde el campo científico, habida cuenta de su incontestable valor simbólico y económico.

Si atendemos al Anuario de Estadísticas Culturales 2017, publicado por el Ministerio de Educación, Cultura y Deporte, observamos que la industria del libro en España constituye un importante motor económico del ámbito cultural, ya que aporta el 0,8 \% del PIB total y el 33,7 \% del conjunto de actividades culturales. A pesar de la crisis, este es un sector que ha dado muestras de gran solidez y capacidad de adaptación en nuestro país, a tenor del incremento sostenido de la actividad empresarial relacionada con el ámbito editorial.

Así, se puede constatar que en 2016 un total de 281 nuevas editoriales - todas independientes - iniciaron su andadura en España, alcanzando la cifra de 3.026 editoriales en activo a nivel nacional, un 16,1 \% más que en 2015 . Geográficamente estas editoriales se distribuyeron como vemos en la tabla 1.

Estas cifras muestran que Andalucía (30 editoriales) es la comunidad autónoma donde mayor número de editoriales independientes — después de Madrid (70 editoriales) y Cataluña (61 editoriales) - surgieron en 2016, I0 que pone de manifiesto que la actividad editorial en nuestra comunidad es un sector en auge.

\section{Gráfico 1. Aportación al PIB de las actividades culturales por sectores (2015)}

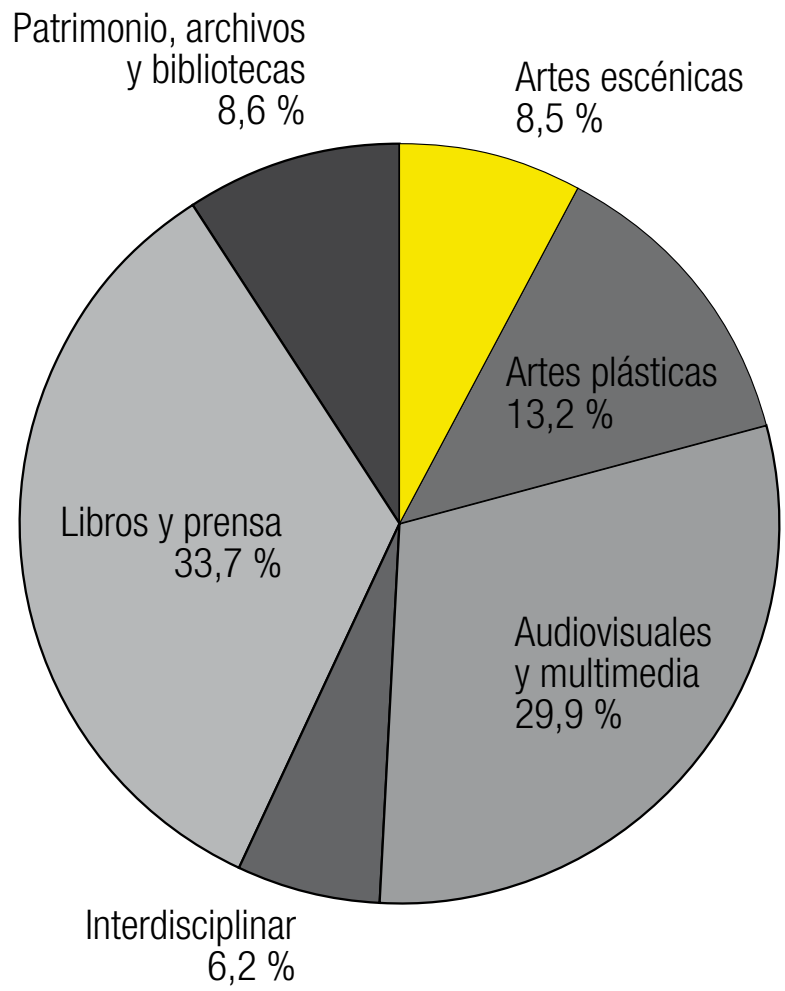

Fuente: MECD. Cuenta Satélite de la Cultura en España. Base 2010.

En virtud de esta realidad nace el proyecto de investigación EDITANDA, financiado por el Centro de Estudios Andaluces en 2014', cuyo principal objetivo ha sido analizar la situación de la edición independiente en Andalucía. Y con este horizonte, hemos formulado algunos interrogantes de partida: ¿cómo ha afectado la doble crisis de la economía española y del sector a la industria editorial en Andalucía? ¿De qué modo se comportan en nuestra comunidad las editoriales independientes? ¿Cómo se ha transformado la visión de la edición independiente en nuestro horizonte cultural y social? E incluso, ¿qué significa ser una editorial independiente en Andalucía hoy? Para responder a estas preguntas, nuestro proyecto ha llevado a cabo una investigación que ha dado como resultado la elaboración de un primer estudio de la edición independiente andaluza en 2016, y una posterior actualización de datos y 


\section{Tabla 1. Altas de agentes editores por distribución geográfica y naturaleza jurídica (2016)}

\begin{tabular}{|c|c|c|c|c|}
\hline CC.AA. & $\begin{array}{l}\text { Organismos } \\
\text { de las } \\
\text { Administraciones } \\
\text { públicas }\end{array}$ & $\begin{array}{l}\text { Autores- } \\
\text { editores }\end{array}$ & $\begin{array}{l}\text { Editoriales } \\
\text { privadas }\end{array}$ & Total \\
\hline Andalucía & & & 30 & 30 \\
\hline Aragón & _- & & 5 & 5 \\
\hline Asturias, Principado de & - & & 5 & 5 \\
\hline Balears, Illes & _- & & 8 & 8 \\
\hline Canarias & 1 & & 5 & 6 \\
\hline Cantabria & _- & & 3 & 3 \\
\hline Castilla y León & - & & 14 & 14 \\
\hline Castilla- La Mancha & _- & & 10 & 10 \\
\hline Cataluña & _- & & 61 & 61 \\
\hline Comunidad Valenciana & $\overline{1}$ & & 27 & 28 \\
\hline Extremadura & _- & & _- & _- \\
\hline Galicia & _- & & 15 & 15 \\
\hline Madrid, Comunidad de & - & & 70 & 70 \\
\hline Murcia, Región de & _- & & 11 & 11 \\
\hline $\begin{array}{l}\text { Navarra, Comunidad } \\
\text { Foral de }\end{array}$ & - & & 4 & 4 \\
\hline País Vasco & _- & & 10 & 10 \\
\hline La Rioja & _- & & 1 & 1 \\
\hline Ciudad de Ceuta & _- & & _- & _- \\
\hline Ciudad de Melilla & _- & & _- & _- \\
\hline Total & 2 & - & 279 & 281 \\
\hline
\end{tabular}

Fuente: MECD. Panorámica de la edición española de libros 2016.

análisis global en 2017. Los resultados que aquí presentamos acerca de este fenómeno editorial son fruto de un trabajo continuado que abre múltiples ventanas a la reflexión crítica en lo que habría de ser un observatorio permanente de la edición independiente en Andalucía.

\section{Criterios de selección y metodología: ¿qué es ser una editorial independiente en Andalucía?}

\begin{abstract}
Para elaborar nuestro estudio sobre la edición independiente en Andalucía hemos realizado, en primer lugar, una selección de editoriales sobre la base de tres criterios fundamentales (para su consideración como independientes): estar registrada como editorial andaluza en la base de datos de editoriales españolas del ISBN; haber publicado al menos un libro en el año 2016; y poseer un catálogo (o como mínimo una colección) de índole literaria. Quedaron incluidas mediante dicho procedimiento librerías y asociaciones culturales que, no estando registradas oficialmente como editoriales, producen periódicamente pequeñas publicaciones y han registrado sus libros con ISBN cumplimentando con su nombre el apartado «editorial». Del catálogo, se excluyó a las editoriales pertenecientes a grandes grupos nacionales o internacionales - aunque no así a grupos locales-, editoriales institucionales y también a las editoriales dedicadas de forma exclusiva a la autoedición con fines lucrativos.
\end{abstract}

Conforme a estos criterios se han seleccionado un total de 100 editoriales en 2017 y se ha elaborado una ficha de cada una de ellas, partiendo de datos públicos e información facilitada por los propios editores, así como de una encuesta que combinaba preguntas de análisis cuantitativo y cualitativo referentes a la identidad de la editorial y a la estructura de su catálogo, pero también a la realidad material e inmaterial que constituye el valor de su proyecto editorial.

El número de editoriales contactadas y que respondieron a nuestra encuesta, según su distribución geográfica por provincia, se muestra en la gráfica 2.

Hemos de precisar que esta encuesta fue respondida en un primer estudio realizado en 2016 por 54 editoriales, entre 102 que cumplían los criterios establecidos. En la actualización de datos que hemos llevado a cabo en 2017, se ha disminuido el corpus en dos, pero se ha ampliado la participa- 


\section{Gráfico 2. Participación año 2017}

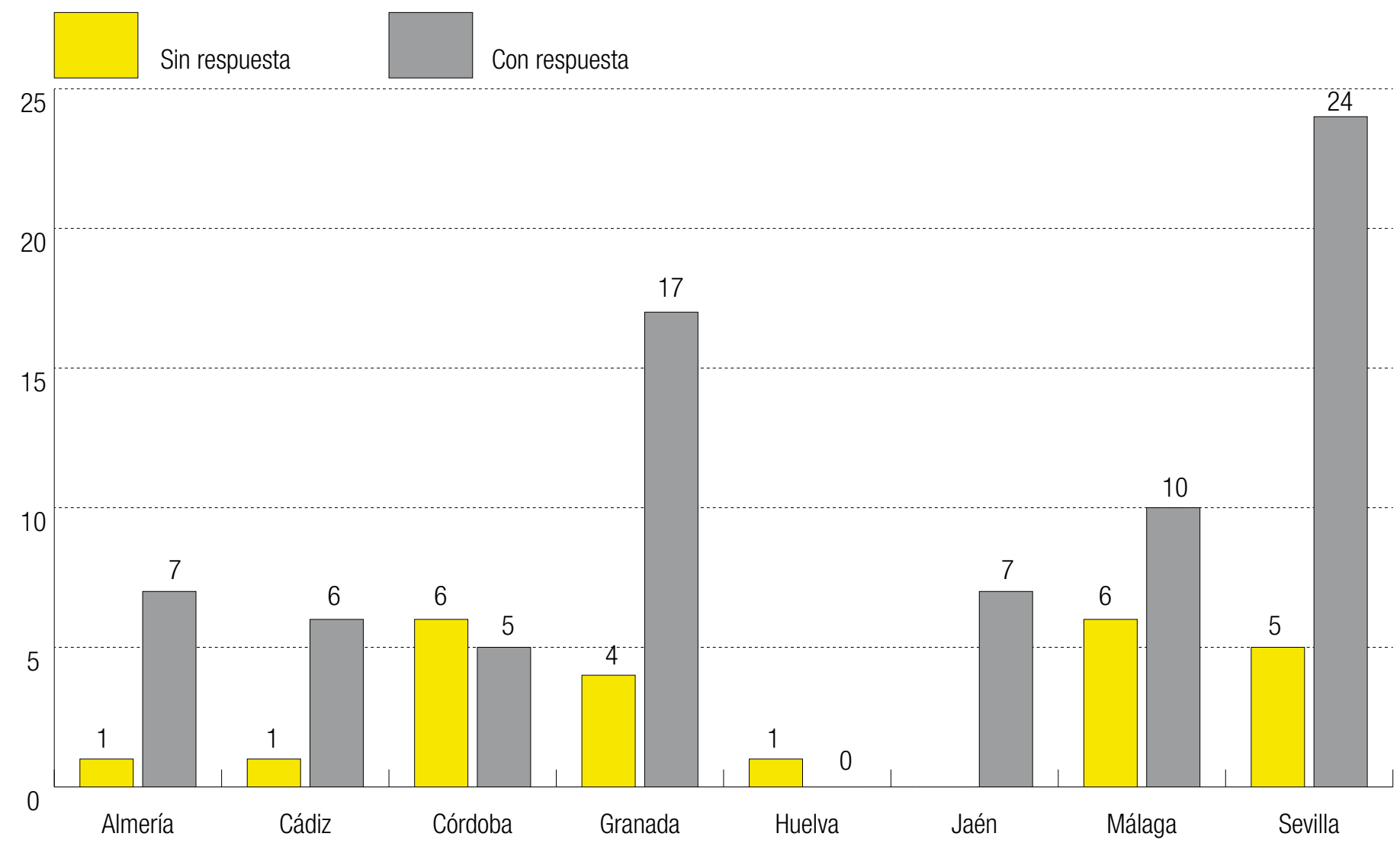

Fuente: elaboración propia a partir de los datos reflejados en el presente trabajo.

ción a 76 editoriales. De las ocho provincias que conforman el mapa andaluz, los porcentajes de participación en los diferentes años son los que aparecen en el gráfico 3.

Mientras que en Almería, Córdoba y en Huelva se mantienen prácticamente los mismos datos de participación en 2016 y 2017, en el resto de provincias el número de participación se ha visto incrementado de manera significativa en la última actualización de información. En Cádiz, por ejemplo, frente al $71 \%$ de participación en 2016, asistimos al 85,7 \% en 2017; en Granada, la participación se incrementó de un 50 \% en 2016 a un $81 \%$ en 2017; por otro lado, en Jaén, el 33,3\% de editoriales seleccionadas contestó la encuesta en 2016, frente al $100 \%$ en 2017. Málaga pasó de un 52,9 \% en 2016 a un 62,5 \% en 2017 y, por último, los datos de participación en Sevilla para los años 2016 y 2017 fueron del $50 \%$ y 82,8 \%, respectivamente. ¿Por qué? Nuestra conclusión es que el sector ha tomado conciencia del interés que está suscitando la efervescencia de editoriales independientes en el mundo académico y de la importancia que supone la participación en una investigación científica rigurosa —y muy visible — como la desarrollada por el proyecto EDITANDA. En este sentido, también han influido el congreso de editoriales independientes organizado en la Universidad de Granada en 2015, 'Congreso Internacional de Editoriales Independientes: Patrimonio Literario y Mercado Editorial'2; la mesa redonda 'El valor de las independientes', organizada por el Centro de Estudios Andaluces en 2016 con ocasión de la Feria del Libro de Granada3; y la publicación del libro A pulmón (o sobre cómo editar de forma independiente en español/4), que ha tenido gran repercusión autonómica y nacional ${ }^{5}$. 
Gráfico 3. Participación (\%) años 2016 y 2017

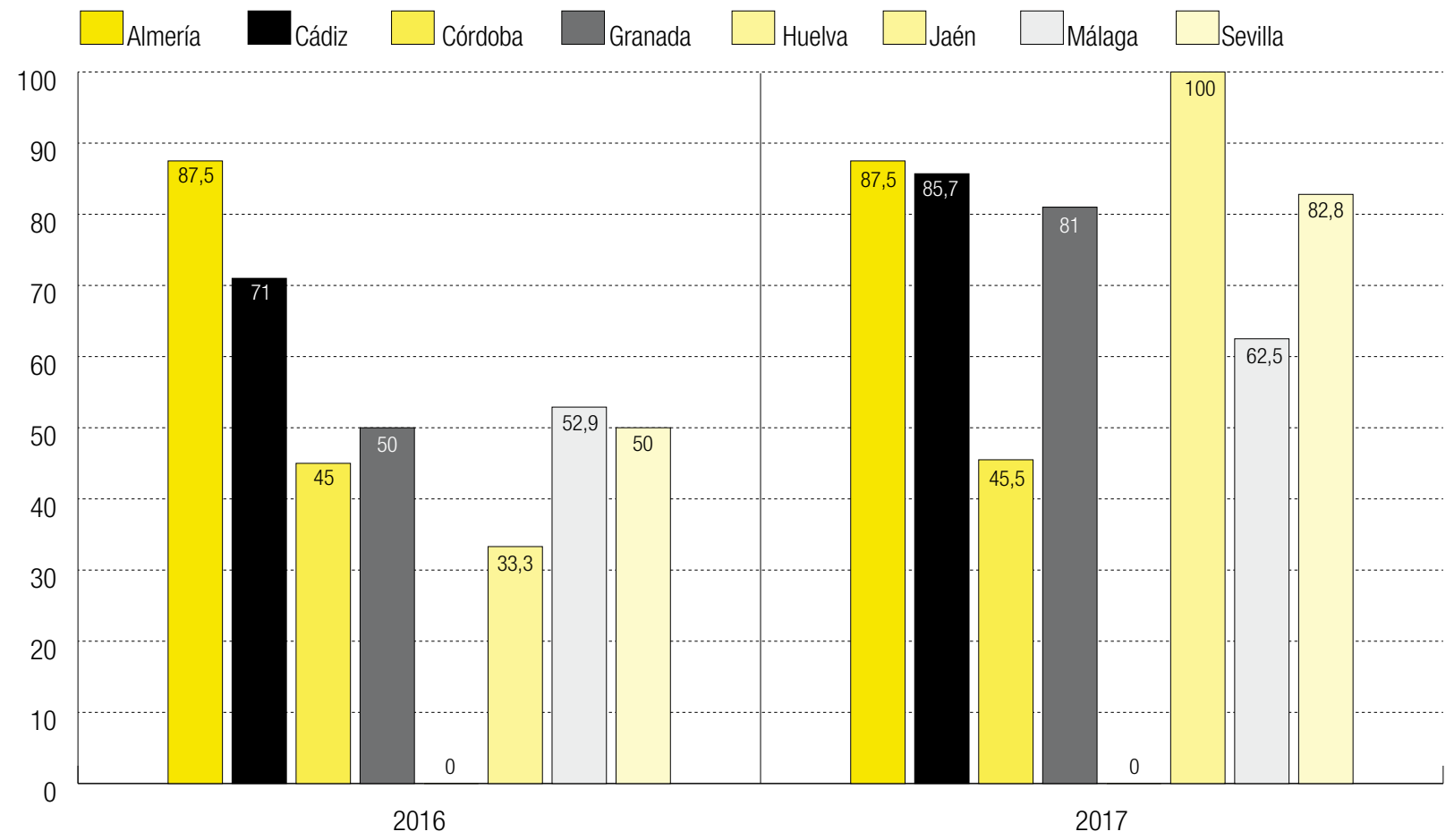

Fuente: elaboración propia a partir de los datos reflejados en el presente trabajo.

\section{Gráfico 4. Distribución editoriales independientes en Andalucía}

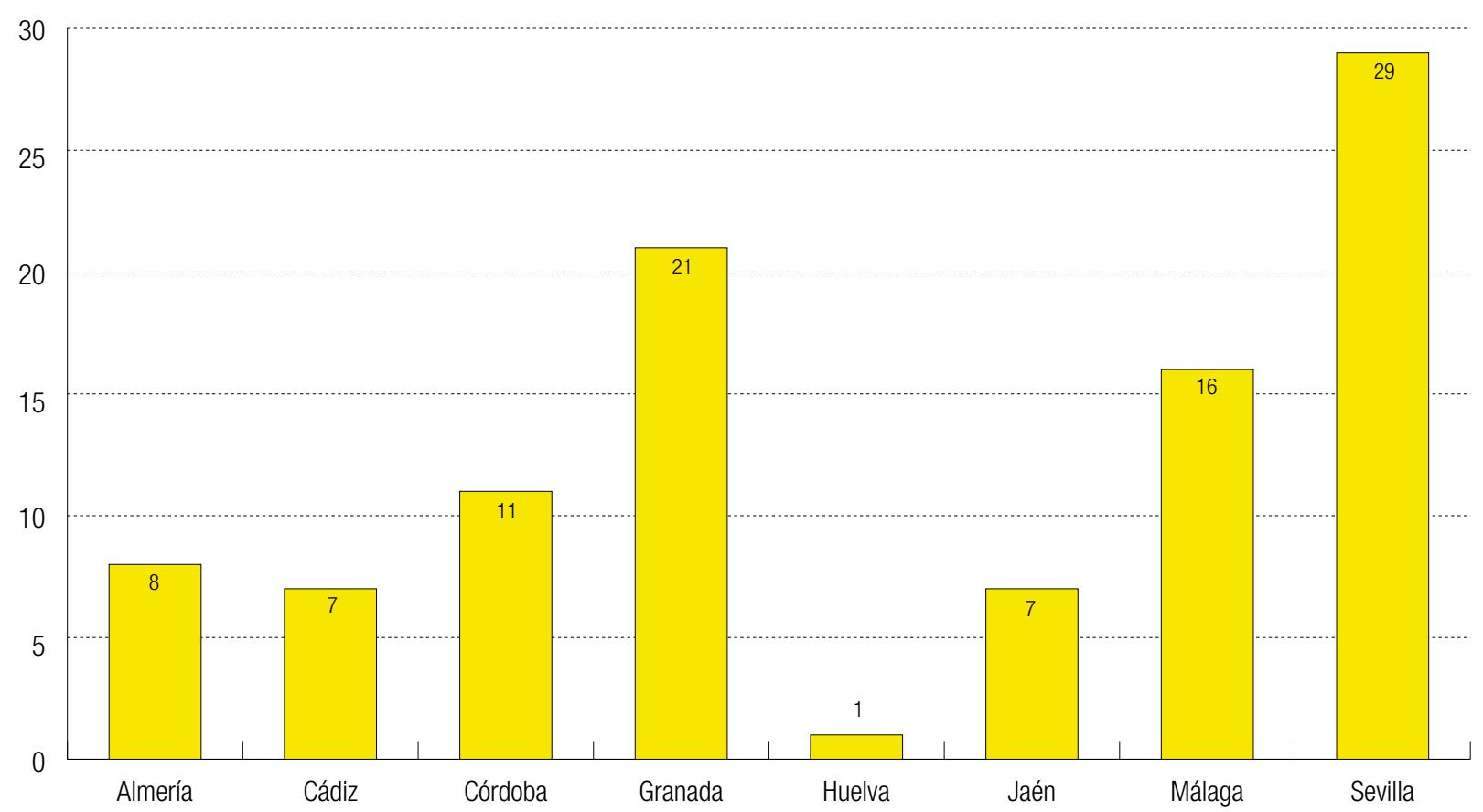

Fuente: elaboración propia a partir de los datos reflejados en el presente trabajo. 


\subsection{Hacia una cartografía de la edición independiente en Andalucía}

Atendiendo a nuestros criterios de selección para la consideración de una editorial como independiente, se han rastreado en Andalucía, como hemos mencionado anteriormente, un total de cien editoriales independientes en
2017, distribuidas por provincias (gráfico 4). De estos datos, se extrae una gran diferencia entre la actividad editorial detectada en cada una de las ocho provincias andaluzas:

\section{Almería:}

- Arráez Editores

- Confluencias

- Ediciones Perdidas

- Editorial Libre Albedrío

- Editorial LXL

- Ginger Ape Books \& Films

- Metáfora

- Ravenswood Books Editorial

\section{Cádiz:}

- Aprendices Visuales

- Cazador de Ratas

- Editorial Cerbero

- Editorial Dalya

- Imagenta

- Kristal Editorial

- Libros Canto y Cuento

\section{Córdoba:}

- Andrómina

- Ánfora Nova

- Bandaáparte

- Berenice

- Detorres Editories

- Editorial Almuzara

- Ediciones Arconte

- Editorial ArcoPress

- Toramico

- La Fragua de Metáforas

- Utopía Libros

\section{Granada:}

- Alhulia

- Aliar Ediciones

- Bárbara Fiore Editora

- Cuadernos del Vigía

- Curva Polar

- Ediciones Dauro

- Ediciones Miguel Sánchez

- Ediciones Tragacanto

- Ediciones Traspiés

- Ediciones Valparaíso

- Editorial Comares

- Editorial Crisol

- Editorial Estratega

- Editorial Nazarí

- Esdrújula Ediciones

- Ediciones Jizo

- Macadán Libros

- La Mirada Malva A. C.

- Libros Maese Gato

- Port-Royal Ediciones

- Sorel \& Bascombe Ediciones Literarias

Huelva:

- Almajara Editorial
Jaén:

- Alcalá Grupo Editorial

- Editorial Amor de Madre

- Editorial Maolí

- Editorial Mil y un Cuentos

- Entrelibros

- Líberman Grupo Editorial

- Editorial Zumaque

\section{Málaga:}

- Canica Books

- Corona del Sur

- Ediciones Algorfa

- Ediciones Azimut

- Ediciones de Aquí (Eda Libros)

- Ediciones El Antro

- Ediciones El Transbordador

- Editorial La Calle

- Lengua Verde Libros

- Librería Hispania Ediciones

- Libros del Genal

- Los Libros de la Frontera

- NubeOcho Ediciones

- Sally Books, Sonolibro

- Zut Ediciones
Sevilla:

- Aedea Libros

- Anantes

- Babidi-bú

- Cangrejo Pistolero

- Carlinga Ediciones

- Donbuk Editorial

- Ediciones Albores

- Ediciones Alfar

- Ediciones de la Isla de Siltolá

- Ediciones en Huida

- Ediciones Sora

- Editorial Arma Poética

- Editorial Atrapasueños

- Editorial Bucéfalo

- Editorial El Sendero

- Editorial Renacimiento

- Editorial Premium

- El Paseo Editorial

- Crononautas

- Karima Editora

- Kokoro Editorial

- Libros de la Herida

- Los Papeles del Sitio

- Maclein y Parker

- Padilla Libros

- Tres Tigres Tristes

- Triskel Ediciones

- Vitela Gestión Cultural y Editorial

- Ultramarina 
Sin duda, es significativa la gran proliferación de editoriales independientes en provincias como Sevilla 0 Granada frente a la poca actividad de pequeños emprendimientos en Huelva, a pesar de ser Punta Umbría la sede de EDITA (Encuentro Internacional de Editores Independientes) y del Salón del Libro Iberoamericano. Sin duda, las condiciones materiales que dan soporte al ámbito cultural y el desarrollo económico de cada provincia explican este desequilibrio.

Dentro de las ocho provincias andaluzas, la localización de estas editoriales es dispar: mientras que la mayor parte de editoriales independientes en Almería y Cádiz están situadas en pueblos o localidades ajenas a la capital; en Córdoba, Huelva y Jaén, las editoriales se reparten de manera más o menos equitativa entre la capital y otras localidades de la provincia. Por otro lado, en Granada, Málaga y Sevilla, la mayor presencia de editoriales independientes está ubicada en las grandes ciudades, como se puede observar en el gráfico 5.

Estos datos ponen de manifiesto que la edición independiente en nuestra Comunidad no está restringida a las grandes ciudades o capitales de provincia sino que se trata de una actividad que se expande de forma casi equitativa entre las grandes ciudades y las localidades más pequeñas, es decir: periféricas. De este modo, al tiempo que encontramos editoriales independientes en las capitales de cada una de las provincias que conforman el mapa andaluz, hallamos también pequeños sellos en núcleos poblacionales marginales como Lachar (Ediciones Tragacanto), Viator (LXL), Rute (Ánfora Nova), Palma del Río (Almuzara, Berenice, ArcoPress y Toramico), Ogijares (Sores \& Bascombe) o Dúrcal (La Mirada Malva A.S.). En el gráfico 6 presentamos el reparto de editoriales independientes en capitales de provincias y otras localidades de Andalucía:

A la vista de estas cifras, se justifica el carácter local y periférico de muchas de estas editoriales, entendiendo que dicha opción no se debe solo a criterios económicos sino también a la voluntad de profundizar en la historia de sus respectivas localidades y provincias. Este supuesto se funda en las respuestas aportadas por las editoriales en las encuestas que hemos realizado, donde encontramos líneas editoriales basadas expresamente en el fomento de autores y temas locales. Es el caso de las granadinas Ediciones Miguel Sánchez, Port-Royal Ediciones o Editorial Crisol, de las editoriales jienenses Entrelibros y Líberman Grupo Editorial y de las editoriales malagueñas Ediciones Algorfa y Lengua Verde Libros. Estos sellos declaran como política editorial la voluntad de escribir la intrahistoria de las localidades andaluzas a las que pertenecen, creando espacios de escritura marginal que habrían de llenar un vacío cultural del que se sienten responsables como miembros de una determinada comunidad.

\section{Gráfico 5. Localización de editoriales independientes andaluzas (2017)}

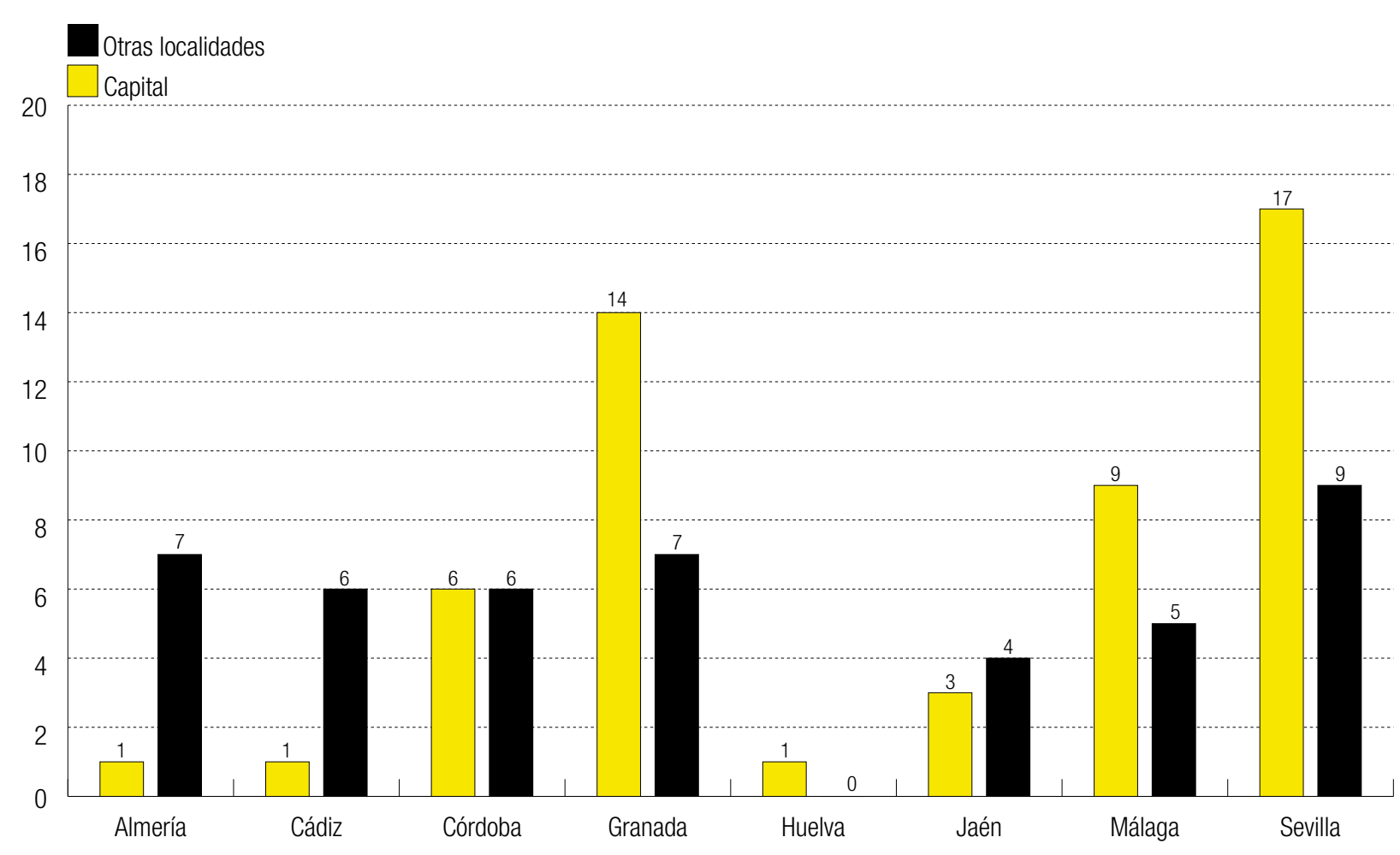

Fuente: elaboración propia a partir de los datos reflejados en el presente trabajo. 
Gráfico 6. Localización editoriales andaluzas

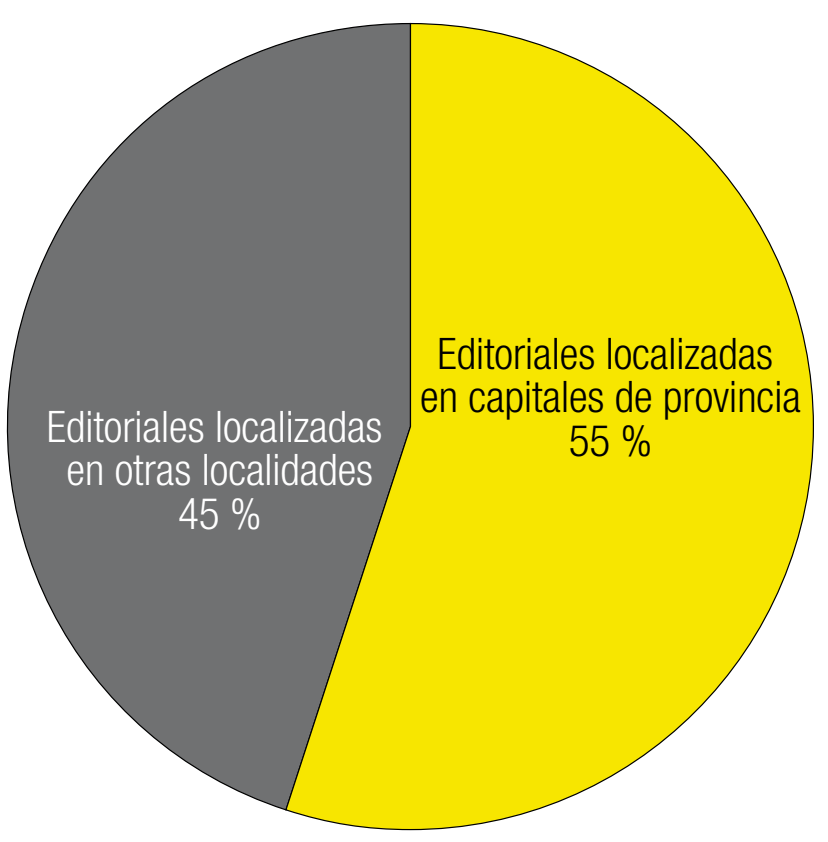

Fuente: elaboración propia a partir de los datos reflejados en el presente trabajo.

Asimismo, resulta destacable el hecho de que las obras publicadas por estas editoriales frecuenten a menudo géneros literarios «menores» como son la poesía o el álbum ilustrado, cuyo riesgo asumen en menor medida las editoriales dependientes de grandes conglomerados. Si comparamos los géneros publicados por las editoriales catalogadas en cada una de las provincias andaluzas, encontramos los datos presentados en la tabla 2.

\section{Tabla 2. Géneros publicados por las editoriales independientes en Andalucía}

\begin{tabular}{|c|c|c|c|c|c|}
\hline & $\begin{array}{l}\text { N. }{ }^{\circ} \text { edit. } \\
\text { Narrativa }\end{array}$ & $\begin{array}{l}\text { N. }{ }^{\circ} \text { edit. } \\
\text { Poesía }\end{array}$ & $\begin{array}{l}\text { N. }{ }^{\circ} \text { edit. } \\
\text { Teatro }\end{array}$ & $\begin{array}{l}\text { N. }{ }^{\circ} \text { edit. } \\
\text { Ensayo }\end{array}$ & $\begin{array}{l}\text { N. }{ }^{0} \text { edit. } \\
\text { Otros }\end{array}$ \\
\hline Almería & 5 & 4 & 0 & 2 & 4 \\
\hline Cádiz & 5 & 4 & 1 & 2 & 5 \\
\hline Córdoba & 11 & 8 & 0 & 7 & 7 \\
\hline Granada & 18 & 16 & 1 & 6 & 13 \\
\hline Huelva & 1 & 1 & 0 & 0 & 0 \\
\hline Jaén & 6 & 4 & 0 & 0 & 4 \\
\hline Málaga & 13 & 6 & 0 & 0 & 6 \\
\hline Sevilla & 25 & 18 & 3 & 11 & 13 \\
\hline Total & 84 & 61 & 5 & 34 & 52 \\
\hline
\end{tabular}

Fuente: elaboración propia a partir de los datos reflejados en el presente trabajo.
La edición independiente en nuestra Comunidad no está restringida a las grandes ciudades o capitales de provincia, sino que se trata de una actividad que se expande de forma casi equitativa entre las grandes ciudades y las localidades más pequeñas, es decir: periféricas

A tenor de la información representada en esta tabla y teniendo en cuenta que la mayoría de las editoriales diversifica su oferta en distintos géneros, la publicación de narrativa es la mayoritaria en nuestra región (84 de 100 editoriales), seguida por la poesía (61 de 100 editoriales), y de otros géneros, entre los que destacan los álbumes ilustrados y las biografías y crónicas (52 de 100 editoriales), el ensayo (34 de 100 editoriales) y por último, el género dramático, cultivado únicamente por cinco editoriales en Andalucía: una en Cádiz, una en Granada y tres en Sevilla.

De esta realidad podemos inferir que las editoriales independientes andaluzas asumen riesgos que las grandes editoriales evitan, enfocando su línea editorial a géneros —además del narrativo - menos comerciales, tales como la poesía, el álbum ilustrado, la literatura infantil o la literatura fantástica. En este sentido, en Andalucía encontramos editoriales independientes que publican de forma exclusiva alguno de estos géneros o subgéneros literarios considerados «menores»: Editorial Maolí y Curva Polar (poesía); Bárbara Fiore Editora, Ediciones Mil y Un Cuento, NubeOcho Ediciones, SaIly Books y Tres Tigres Tristes (libros ilustrados); Libre Albedrío, Aprendices visuales, Lengua Verde Libros y Babidi-bú (literatura infantil); o Ediciones El Transbordador y Carlingo Ediciones (literatura fantástica). De la misma manera, existen editoriales que en su afán de especializarse ya no definen su línea editorial a partir de géneros literarios sino a partir de temáticas como el feminismo (Editorial Crononauta, Amor de Madre, La Calle), el LGTB o el homoerotismo (Ediciones El Antro, Amor de Madre y La Calle), corrientes que no son prioritarias para los grandes conglomerados editoriales.

También es frecuente, cuando analizamos el perfil editorial, la insistencia en la atención a autores jóvenes a los que estos sellos independientes se afanan en dar la oportunidad de publicar. Así lo manifiestan la editorial alme- 
riense Ravenswood Books Editorial, la granadina Kristal Editorial, la cordobesa Andrómina o las granadinas Aliar y Cuadernos del Vigía, que apuestan desde sus líneas editoriales por dar voz a jóvenes autores desconocidos en el panorama literario. Esta labor es cardinal para renovar el sistema literario, asumiendo riesgos que una gran editorial no contempla si el autor no posee cierto reconocimiento — capital simbólico— previo.

Por otro lado, si estudiamos la definición de «editorial independiente» que nos proporcionan las editoriales que han contestado a nuestra encuesta, hay una tendencia mayoritaria que oscila entre la identificación del término con la libertad absoluta y la no pertenencia a grandes grupos editoriales; y por otro lado, aunque en menor grado, la necesidad de establecer criterios de calidad que se compatibilicen con los intereses económicos. Así constatamos que más de una treintena de editoriales repartidas en los diferentes puntos de Andalucía hacen alusión a la equivalencia de «editorial independiente» con la no pertenencia a un gran conglomerado editorial o a presiones económicas externas; esto es: una editorial que puede permitirse el lujo de editar lo que quiere «independientemente» de las demandas del mercado. A este respecto, Arráez Editores (Almería) responde: «Que no está controlada política, económica, social o culturalmente por nadie. Libertad absoluta»; Ediciones Perdidas (Almería): «Editar lo que nos parece, cómo nos parece, sin dependencias económicas de la administración ni del mercado»; Libros Canto y Cuento (Cádiz): «Una editorial fuera de presiones empresariales, institucionales e incluso comerciales. Esa que a la hora de publicar prima sobre todo la calidad del libro, al margen de cualquier otro parámetro»; o Port-Royal Editorial (Granada): «La que lleva o puede llevar a cabo su actividad con criterio propio [...] sin que tenga necesidad de estar supeditada a la concesión de ayudas públicas o privadas».

\section{La definición de «editorial} independiente» que las editoriales han contestado mayoritariamente oscila entre la libertad absoluta y la no pertenencia a grandes grupos editoriales y, por otro lado, aunque en menor grado, la necesidad de establecer criterios de calidad que se compatibilicen con los intereses económicos
Otra respuesta que se repite en los cuestionarios recabados es la importancia del valor literario de la obra, más allá de las oscilaciones del mercado. De este modo, nos encontramos con la definición de la Editorial Libre Albedrío (Almería), que apunta que una editorial independiente es la «que mantiene su identidad y pone en valor la calidad literaria de sus obras por encima de las modas y los devaneos del mercado, la que se mantiene firme en su línea editorial basándose en el carácter eminentemente cultural que debe tener una editorial y en la calidad de contenidos» 0 la de Editorial Nazarí (Granada), que sostiene que una editorial independiente es «aquella que tiene clara su línea editorial y la mantiene independientemente de factores externos, no se basa en las modas o se fija solamente en la rentabilidad económica, sino que ve mucho más allá del mero producto económico».

De forma insistente, los sellos interrogados subrayan como elemento clave de su identidad el estilo del editor (Ediciones Perdidas, Maese Gato Editorial, Rasenswood Books Editorial, Jizo Ediciones, Port-Royal Ediciones). La editorial se constituiría a sí misma como un lector activo: los gustos del propio editor serán la seña de identidad de la editorial, más allá de la estética literaria del momento. Algunas editoriales, en su selección de libros, asumen su voluntad de encarnar un papel social o educativo, considerando que el criterio ético se enfrenta en este punto directamente con el criterio económico. Sorel \& Bascombe (Granada) señala el «rol social» que debe tener una editorial independiente al «hacerse cargo de necesidades locales haciendo prevalecer el valor cultural de la empresa por encima de todo lo demás»; 0 la editorial malagueña Los Libros de la Frontera que afirma que una editorial independiente debe «mejorar la sociedad y el planeta en que viven».

Atendiendo también a las respuestas de nuestro estudio, puede constatarse una fuerte dependencia de la editorial independiente con la naturaleza del mercado del libro en la actualidad, dominado por oligopolios. La editorial independiente habría de surgir de la necesidad de cubrir los yacimientos de mercado que dejan al descubierto los grandes conglomerados. En relación con esto, Aprendices Visuales (Cádiz) indica que una editorial independiente es aquella «que nace para publicar libros que las editoriales existentes no toman en consideración» y a su vez, Sorel \& Bascombe Editorial (Granada) señala que una editorial independiente surge con el objeto «de realizar un aporte cultural a la sociedad y de rellenar un hueco de sombra que los canales oficiales obvian». También existen editoriales entre las encuestadas que, lejos de apropiarse del término «independiente», se deslindan de esta etiqueta y prefieren definirse como una editorial pequeña que, debido a su infraestructura, no puede hacer frente a las grandes editoriales. Este es el caso de la almeriense Metáfora y de las sevillanas Renacimiento, Cuadernos del Vigía y Crononautas.

En su voluntad de ofrecer un producto diferenciado, muchas de estas editoriales destacan que, dentro de su vocación de independientes, se encuentra 
el cuidado del libro, con ejemplos de publicaciones artesanales, ilustradas o realizadas con materiales y formatos experimentales (Libre Albedrío Editores, Utopía Libros, Los Papeles del Sitio, Bandaàparte Editores, Cuadernos del Vigía, Líberman Grupo Editor, Ediciones Azimut, etc.). Algunas reconocen que sus criterios y líneas editoriales se han visto influidas por la crisis económica, obligándoles a reinventarse: verbigracia, la editorial malagueña Libros del Genal, que cuenta cómo tras la crisis tuvo que aunar los servicios de librería con los de edición a demanda y la autoedición. En esto, las editoriales andaluzas objeto de nuestro análisis han optado por una diversificación y ampliación de sus perfiles, lo que les ha permitido sobrevivir haciendo más labor de edición por menos dinero.

En conclusión, y a la luz de toda la información desgranada, puede extraerse que -aunque sigue siendo complejo definir qué es una editorial independiente hoy día - la edición independiente en Andalucía se define sobre una base vocacional en los perfiles de las editoriales, donde priman el impulso creador, la originalidad y un modo de producción - y beneficio - a medio plazo, frente al "cortoplacismo» propio de los oligopolios. Algunas de estas editoriales declaran explícitamente considerarse fuera del mercado editorial, así como del gusto generalizado, mientras otras reconocen que viven de las parcelas de mercado que no cubren los grandes conglomerados. De ahí su interés por escritores jóvenes, noveles y locales, así como por una literatura de corte regional o provincial. No se trata entonces de editoriales que estén dirigidas al gran público sino, por regla general, a la demanda de una marginalidad que, aunque como tal es minoritaria, existe y tiene su cuota de mercado, aun cuando para determinados sellos el factor económico no sea prioritario. Asimismo, estas editoriales se definen al albur de un concepto de literatura —y de edición artesanal— de calidad que juzgan, nuevamente, fuera de los estándares, llegando en ciertos casos a apostar por catálogos estructurados en torno a colecciones temáticas en lugar de géneros, estrategia poco común en las grandes editoriales.

\section{En los márgenes de la edición independiente: ser mujer y ser andaluz}

Otra variable analizada por el proyecto EDITANDA a través del método de encuestas es la que tiene que ver con la presencia de la mujer y de lo andaluz en los catálogos de las editoriales independientes andaluzas. ¿Apuestan las editoriales independientes de nuestra comunidad por literaturas marginales, subalternas o descentradas? ¿Constituye la edición de escritoras y autores locales un signo de independencia de estas editoriales?

Si tenemos en cuenta el análisis de los datos obtenidos en nuestra muestra, podemos resumir — desde un punto de vista cuantitativo — la presencia de la mujer y de lo andaluz en los porcentajes que expresamos en la tabla 3.

\section{Tabla 3. Mujeres escritoras y autores andaluces publicados en editoriales independientes andaluzas (2017)}

\begin{tabular}{lllll} 
& $\begin{array}{l}\text { Mujeres } \\
\text { escritoras } \\
\text { por provincia } \\
\text { (\%) }\end{array}$ & $\begin{array}{l}\text { Mujeres } \\
\text { escritoras } \\
\text { sobre el total } \\
\text { de mujeres } \\
\text { escritoras en } \\
\text { Andalucía (\%) }\end{array}$ & $\begin{array}{l}\text { Autores } \\
\text { andaluces } \\
\text { por } \\
\text { provincia } \\
(\%)\end{array}$ & $\begin{array}{l}\text { Autores } \\
\text { andaluces } \\
\text { sobre el total } \\
\text { de autores } \\
\text { andaluces en } \\
\text { Andalucía (\%) }\end{array}$ \\
\hline Almería & 43,95 & 7,24 & 70,05 & 10,47 \\
Cádiz & 45,07 & 4,18 & 71,12 & 5,85 \\
Córdoba & 30,95 & 2,54 & 63,09 & 4,61 \\
Granada & 19,97 & 32,5 & 23,62 & 34,16 \\
\hline Huelva* & - & - & - & - \\
\hline Jaén & 35,74 & 2,74 & 32,34 & 2,2 \\
Málaga & 33,3 & 15,83 & 42,41 & 17,89 \\
Sevilla & 33,91 & 34,95 & 27,07 & 24,79
\end{tabular}

Fuente: elaboración propia a partir de los datos de reflejados en el presente trabajo. Nota *: no se tienen datos. 


\subsection{Presencia de escritoras en los catálogos de las editoriales independientes de Andalucía}

Con respecto al género de los autores que publican en las editoriales independientes andaluzas, se comprueba que ninguna de las provincias supera el $50 \%$ de escritoras editadas, siendo Cádiz y Almería las provincias en las que más destaca la presencia de obras de mujeres, superando el $40 \%$ en cada una de ellas. Sin embargo, en cómputos globales a nivel editorial, es en Sevilla y Granada donde de cada cien mujeres escritoras que encontramos en Andalucía, se localizan la mayor parte: $34,95 \%$ y $32,5 \%$ respectivamente. En este sentido, pudimos constatar, después de analizar los resultados obtenidos en el estudio, que una de nuestras hipótesis de partida era errónea. Al contrario de lo que pensábamos al comienzo de nuestra investigación, la cuestión del género no aparece vinculada, especialmente, con la independencia editorial: las editoriales independientes andaluzas, salvo excepciones, no prestigian la publicación de obras escritas por mujeres, sino que sus políticas de publicación - y sus catálogos - neutralizan la cuestión de género. A lo sumo, y tal vez a modo de resistencia y como tímido gesto de «independencia», estos sellos despojan la producción literaria de escritoras del componente «femenino» y diferenciador que suele prodigarse en algunas editoriales grandes. No sería, por tanto, el género uno de los parámetros prioritarios de edición para las independientes de Andalucía, sino que la publicación de obras de mujeres es consecuencia subsidiaria de otros objetivos: la necesidad de reeditar obras descatalogadas con gran valor para el ecosistema literario, la promoción y descubrimiento de jóvenes escritores, de autores andaluces con talento literario o la defensa de géneros secundarios - entre los que destaca la literatura infantil o la literatura fantástica-.

A la pregunta: «¿Cuál es el porcentaje de mujeres aproximado que publican en su editorial?», algunos sellos han indicado que llevan a cabo la elección de los manuscritos a ciegas, sin conocimiento sobre la identidad del autor. Así, por ejemplo, la editorial sevillana Palimpsesto (ahora sin actividad) afirma: «No miramos la biografía del autor hasta que se decide la publicación del título. Primero atendemos al texto, lo demás es accesorio». Igualmente, la editorial Dalya (Cádiz) asegura que tiene en su catálogo un 20 \% de autoras, el mismo porcentaje de manuscritos que reciben; y la editorial sevillana Premium explica que solo el $10 \%$ de su catálogo está ocupado por escritoras porque del total de manuscritos que reciben, solo un $5 \%$ son de mujeres, algo que les gustaría que aumentara de forma significativa con el tiempo.

Sin embargo, existen excepciones - pocas - a esta situación. La editorial sevillana Aeda Libros señala como uno de sus objetivos producir libros de todas las temáticas y de todos los públicos —atendiendo a la calidad literaria - pero que tengan como seña el empoderamiento femenino. Como ellos mismos indican, la mayoría de sus libros infantiles, de novela o de poesía están orientados a «incentivar la libertad femenina». Además, avalan su intención con un porcentaje de mujeres publicadas cercano al $80 \%$, y con un total de obras con temática del empoderamiento femenino que se acerca al $90 \%$ de sus publicaciones. Al igual que Aeda Libros, la editorial gaditana Cerbero se autodefine como una editorial feminista que trabaja duro para hacer de su sello «un espacio seguro y libre de prejuicios», que intenta «romper la brecha de género que existe en la literatura.» Debido a esto, declaran recibir muchos manuscritos escritos por mujeres y más del $60 \%$ de su catálogo está copado por autoras. Por otro lado, la editorial sevillana Crononautas define su línea editorial a partir de una reivindicación marginal en nuestro mercado literario: «literatura de género con perspectiva de género», que pretende dar visibilidad a obras y personas «que aborden temas de género y diversidad y tengan identidades que estén fuera del espectro de la masculinidad.» Por ello, el $100 \%$ de su catálogo está conformado por obras escritas por mujeres, al igual que ocurre con la editorial malagueña Ediciones El Antro. Otras editoriales, como es el caso del catálogo de Aprendices Visuales (Cádiz) está constituido únicamente por autoras mujeres y andaluzas. También Andrómina (Córdoba), destaca por haber publicado el Premio Internacional de Poesía para mujeres Leonor de Córdoba.

\subsection{Presencia de escritores andaluces en los catálogos de editoriales independientes de Andalucía}

Si la presencia de mujeres no supone un rasgo distintivo o característico de la independencia editorial en Andalucía, sí que lo es, en mayor medida, la importancia de lo andaluz. Teniendo en cuenta las cifras que hemos obtenido durante nuestra investigación, a excepción de Granada, Jaén y Sevilla, el resto de provincias superan el $40 \%$ de obras de escritores andaluces, destacando Cádiz, Almería y Córdoba, que tienen más de un $60 \%$ de andaluces en los catálogos de sus sellos independientes. Sin embargo, en cómputos globales a nivel editorial, es en Granada donde de cada cien escritores andaluces en nuestra Comunidad, se localiza la mayor cifra de las ocho provincias: un 34,16 \%, seguida de Sevilla con un 25,79 \% y Málaga con un 17,89\%. Esto es: aunque el total de escritores andaluces sea mayor en estos casos, porcentualmente y respecto al catálogo de cada sello independiente, apuestan menos por los autores locales que las provincias antes citadas: Cádiz, Almería y Córdoba. Sea como fuere, muchas de las editoriales 
entrevistadas demuestran un claro interés localista o regional, estableciendo como una de sus marcas de identidad la difusión de contenidos propios de cada provincia —ya sean estos geográficos, literarios o culturales—, o de la comunidad autónoma en general.

Como ejemplos de lo expuesto tenemos en Granada Ediciones Miguel Sánchez — especializada en obras de temas locales y guías turísticas - PortRoyal Editorial —que prioriza en su catálogo a autores andaluces y temas locales - y Editorial Crisol — centrada en la edición de novela histórica granadina y nacional - . Por otro lado, Grupo editorial Líberman y Entrelibros (Jaén) explicitan su especial interés en publicar a creadores jiennenses y andaluces, al igual que Ediciones Algorfa en Málaga, que expresa también su compromiso con autores andaluces. Asimismo, la editorial La Serranía (Cádiz) «cuenta con varias colecciones dedicadas a la historia y al patrimonio andaluz». Esta editorial, además, tiene como rasgo de distinción el hecho de que «se especializa en distribuir en puntos atípicos con un total de 1.500 puntos de venta en Andalucía». También en este rubro, Arráez Editores (Almería) define su línea editorial al socaire de la publicación de libros escritos por almerienses o que versan sobra la provincia de Almería. Desde el punto de vista literario, resalta la Editorial Esdrújula de Granada, que cuenta entre sus objetivos de trabajo el interés por difundir tanto las letras granadinas, como a los poetas vinculados con la ciudad. También en Granada, Port Royal trata de editar temas granadinos y andaluces, sin excluir otras opciones.

Por último, y ligado a este aspecto, debemos mencionar la importancia de la distribución regional para estas editoriales, que se convierte en uno de los rasgos de distinción de las independientes andaluzas. En rigor, un gran porcentaje de nuestros encuestados menciona como rasgo definitorio de su sello tanto la difusión de sus libros por el territorio andaluz, como la publicación de premios andaluces. En Sevilla, Ediciones en Huida declara llevar a cabo una distribución directa en el espacio andaluz mediante pequeñas librerías independientes — aproximadamente en diez puntos de venta-. El Sendero, Maclein y Parker (ambas de Sevilla) y La fragua de metáforas (Córdoba), también distribuyen fundamentalmente en Andalucía. Cabe destacar, en este apartado, que algunas de las editoriales independientes que forman parte de nuestro estudio llevan a cabo coediciones con instituciones y otras editoriales que también son andaluzas, razón por la cual es prioritaria la publicación de autores de Andalucía en sus catálogos. Tal es el caso de Bandaàparte Editores (Córdoba) y la editorial Ginger Ape Books \& Films, en Almería.

\section{Perfil económico de las editoriales independientes andaluzas ${ }^{7}$}

Por lo que respecta al análisis económico —condiciones materiales, modos de producción, canales de circulación y modelos de negocio- que se desprende de las respuestas obtenidas en las 76 encuestas realizadas a editoriales independientes de Andalucía, los datos obtenidos son los siguientes:

1. Todos los sellos independientes andaluces cuentan con capital económico privado de base.

2. Todas las editoriales independientes andaluzas, a excepción de la almeriense Ediciones Perdidas y la granadina Ediciones Paralelo (que no ha participado en esta encuesta), apuestan por canales de circulación regulados de las obras editadas, esto es: se registran en depósitos legales y bases de datos de ISBN.

3. Solo el 30,3\% - 23 editoriales - de las encuestadas han recibido 0 reciben subvenciones públicas. Entre estas, no se encuentra ningún sello de Cádiz, tan solo dos de Almería (Arráez Editores y Ginger Ape Books and Films), tres de Córdoba (Andrómina, Ánfora Nova y La Fragua de Metáforas), tres de Jaén (Grupo Alcalá y sus sellos Zumaque y Mil y Un Cuentos) y tres de Málaga (Ediciones de Aquí, NubeOcho Ediciones y Sonolibro). Así, en Granada y Sevilla se localiza el mayor número de editoriales que reciben subvenciones públicas; concretamente, seis en cada provincia: Alhulia, Comares, Cuadernos del Vigía, Esdrújula Ediciones, La mirada Malva y Traspiés en Granada; y Ediciones Alfar, Ediciones El Sendero, Renacimiento, Tres Tigres Tristes, Premium Editorial y Editorial Ultramarina en Sevilla.

\section{Tabla 4. Editoriales encuestadas con subvenciones públicas $\left(n .^{\circ}\right)$}

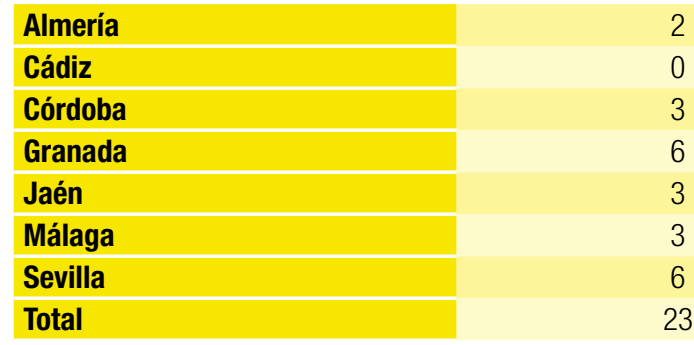

Fuente: elaboración propia a partir de los datos reflejados en el presente trabajo. 
Si atendemos al número de editoriales que ha contestado nuestra encuesta, 76, y revisamos el porcentaje de editoriales que reciben subvenciones en cada una de las provincias, las editoriales de Córdoba con tres de cinco editoriales (60 \%) serían las que más subvenciones reciben o han recibido para editar sus libros. Tras estas, se encontrarían las editoriales jienenses con 42,86 \% de las editoriales encuestadas (tres de siete editoriales), seguidas de Granada con un 35,3 \% (seis de 17 editoriales), Málaga con un $30 \%$ (tres de diez editoriales), Almería con un 28,57 \% (dos de siete editoriales) y SeviIla, donde solo un $25 \%$ (seis de 24 editoriales) afirma haber recibido alguna subvención.

4. En lo referido a la distribución, las independientes andaluzas revelan que solo el $26,3 \%$, es decir 20 sellos, se autodistribuyen y/0 no utilizan distribuidoras comerciales nacionales (la gran mayoría) 0 autonómicas: dos en Almería (Ediciones Perdidas y Rasenwood Book Editorial), tres en Cádiz (Aprendices Visuales, Imagenta y Cerbero), tres en Córdoba (Andrómina, Detorres Editores y La Fragua de Metáforas), cinco en Granada (Aliar, Curva Polar, Tragacanto, Jizo y Sorel \& Bascombe), una en Jaén (Entrelibros), tres en Málaga (Ediciones El Antro, Ediciones Librería Hispania y Sonolibros) y tres en Sevilla (Aeda Libros, Donbuk y El Sendero). Llama la atención que únicamente la editorial más antigua que encontramos en Jaén (1998) se autodistribuya, a pesar de que tres de las siete encuestadas en esta provincia se hayan creado después de la crisis de 2008. También habría que reparar en el hecho de que tres de las seis editoriales encuestadas en Cádiz se autodistribuyan, así como tres de las cinco cordobesas, lo que nos llevaría a pensar que las provincias con menor crecimiento económico, y menor tradición en el sector, según el Instituto Nacional de Estadistica ${ }^{8}$, son las que más se autodistribuyen - a excepción de Jaén-.

\section{Tabla 5. Editoriales encuestadas que se autodistribuyen ( $\left.\mathrm{n}^{\circ}\right)$}

\begin{tabular}{|l|c|}
\hline Almería & 2 \\
\hline Cádiz & 3 \\
\hline Córdoba & 3 \\
\hline Granada & 5 \\
\hline Jaén & 1 \\
\hline Málaga & 3 \\
\hline Sevilla & 3 \\
\hline Total & 20 \\
\hline
\end{tabular}

Fuente: elaboración propia a partir de los datos reflejados en el presente trabajo.
5. De otro lado, solo 31 editoriales, el 40,8 \%, han publicado o publican premios literarios: dos en Almería (Arráez Editores y Ediciones Libre Albedrío), cuatro en Cádiz (Editorial Dalya, Imagenta, Kristal Editorial y Cerbero), cuatro en Córdoba (Andrómina, Bandaàparte, Anfora Nova y La Fragua de Metáforas), siete en Granada (Alhulia, Aliar Ediciones, Bárbara Fiore Editora, Cuadernos del Vigía y Curva Polar), tres en Jaén (Grupo Alcalá, Entrelibros y Editorial Zumaque), cuatro en Málaga (Los Libros de la Frontera, Nube0cho, Sally Books y Sonolibro) y siete en Sevilla (Carlinga Ediciones, Editorial Alfar, La Isla de Siltolá, Editorial El Sendero, Renacimiento, Padilla Libros y Premium Editorial).

\section{Tabla 6. Editoriales encuestadas con premios literarios $\left(\mathrm{n} .{ }^{\circ}\right)$}

\begin{tabular}{|l|c|}
\hline Almería & 2 \\
\hline Cádiz & 4 \\
\hline Córdoba & 4 \\
\hline Granada & 7 \\
\hline Jaén & 3 \\
\hline Málaga & 4 \\
\hline Sevilla & 7 \\
\hline Total & 31 \\
\hline
\end{tabular}

Fuente: elaboración propia a partir de los datos reflejados en el presente trabajo.

Córdoba, con un $80 \%$ de sus editoriales (cuatro de cinco) y Cádiz, con un $67 \%$ (cuatro de seis) serían, con una diferencia significativa, las dos provincias que, en relación con el número de encuestas recopiladas, más premios literarios publican frente a provincias como Almería o Sevilla, donde el porcentaje de editoriales con premios literarios desciende hasta un $29 \%$ en cada una (dos de siete editoriales en Almería y siete de 24 editoriales en Sevilla). Por otro lado, en torno al $40 \%$ de editoriales que cuentan con premios literarios estarían Granada (siete de 17), Jaén (tres de siete) y Málaga (cuatro de diez).

6. El 43,42\% de las editoriales independientes andaluzas (33 de 76) ha realizado y/o realiza coediciones con instituciones privadas y/o públicas: tres en Almería (Arráez Editores, Ediciones Perdidas y Ginger Ape Books and Films), una en Cádiz (Libros Canto y Cuento), cuatro en Córdoba (Andrómina, Bandaàparte, Ánfora Nova y La Fragua de Metáforas), diez en Granada (Alhulia, Aliar, Bárbara Fiore, Ediciones Miguel Sánchez, Tragacanto, Comares, Editorial Nazarí, Esdrújula, Jizo Edciones y Libros Maese Gato), dos en Jaén (Entrelibros y Líberman Grupo Editor), seis en Málaga (Algorfa, Ediciones de Aquí, Libros del Genal, Libros de La Frontera, Nu- 
beOcho y Sonolibro) y siete en Sevilla (Alfar, La Isla de Siltolá, Editorial Atrapasueños, Renacimiento, Karima Editores, Libros de la Herida y Padilla Libro). En Sevilla, además, la editorial Ultramarina tiene programadas en un futuro coediciones con otras instituciones y Aeda Libros y Babidi-bú no se cierran a esta posibilidad.

\section{Tabla 7. Editoriales encuestadas que realizan coediciones(n. $\left.{ }^{\circ}\right)$}

\begin{tabular}{|l|}
\hline Almería \\
\hline Cádiz \\
\hline Córdoba \\
\hline Granada \\
\hline Jaén \\
\hline Málaga \\
\hline Sevilla \\
\hline Total \\
\hline
\end{tabular}

3
1
4
10
2
6
7
33

Fuente: elaboración propia a partir de los datos reflejados en el presente trabajo.

Según podemos observar, el 80 \% de las editoriales encuestadas en Córdoba (cuatro de cinco) afirma hacer o haber hecho en el pasado coediciones con otras editoriales o instituciones; como ocurre en la provincia de Málaga en el 60 \% de los sellos consultados (seis de diez); en Granada, en el 58,82 \% (diez de 17); y en Almería, en el 42,86 \% (tres de siete editoriales). Por otro lado, Cádiz, con una de seis editoriales (16,7\%); Jaén, con dos de siete editoriales (28,57\%); y Sevilla, con siete de 24 editoriales $(29,17 \%)$ son las provincias que, en proporción, menos coediciones realizan.

7. El $38,16 \%$ de las empresas y editoriales encuestadas, 29 de 76 , reconocen abiertamente que se dedican a la autoedición de obras literarias, ya sea con su propia marca o bajo otro sello editorial: dos en Almería (Ediciones Perdidas y LXL), dos en Cádiz (Imagenta y Libros Canto y Cuento), tres en Córdoba (Andrómina, Detorres Editores y Ánfora Nova), seis en Granada (Alhulia, Aliar, Editorial Nazarí, Esdrújula Ediciones, La Mirada Malva y Port-Royal), dos en Jaén (Entrelibros y Líberman Grupo Editor), cuatro en Málaga (Algorda, Libros del Genal, Libros de la Frontera y Sonolibros) y diez en Sevilla (Anantes, Babidi-bú, Albores, Atrapasueños, Bucéfalo, Editorial Arma, Renacimiento, Karima, Padilla Libros y Ultramarina). Encontramos cuatro editoriales (5\%) que no nos responden claramente a la pregunta (una en Almería, una en Córdoba y dos en Sevilla), de lo que podríamos colegir - junto con algunas respuestas que aluden al tema- que la autoedición sigue siendo un tabú en el sector, que habría de comprometer la «independencia» del sello, porque prioriza el capital económico ante el capital simbólico. Por el contrario, 37 sellos, el $48,68 \%$ de las editoriales encuestadas, niega que lleve a cabo prácticas de autoedición, y algunas de ellas se muestran muy críticas al respecto. Este es caso de Ravenswood Books Editorial en Almería, que afirma que la autoedición es contraria a su política editorial; Azimut, en Málaga; y El Paseo Editorial en Sevilla, también se manifiestan contrarios a esta práctica.

\section{Tabla 8. Editoriales encuestadas que autoeditan $\left(\mathrm{n}^{\circ}\right)$}

\begin{tabular}{|l|c|}
\hline Almería & 2 \\
\hline Cádiz & 2 \\
\hline Córdoba & 3 \\
\hline Granada & 6 \\
\hline Jaén & 2 \\
\hline Málaga & 4 \\
\hline Sevilla & 10 \\
\hline Total & 29 \\
\hline
\end{tabular}

Fuente: elaboración propia a partir de los datos reflejados en el presente trabajo.

Si analizamos cada provincia en proporción, donde más se autoedita es en Córdoba con tres de cinco editoriales encuestadas (60 \%); Sevilla, con diez editoriales de 24 (41,67\%); y Málaga, con cuatro de diez editoriales (40\%). Granada, con seis de 17 editoriales (35,3\%); seguida de Cádiz, con dos de seis editoriales (33,3\%), y Almería y Jaén, con dos de siete editoriales $(28,57 \%)$, respectivamente, serían las provincias donde esta práctica se realiza en menor proporción. 


\section{Futuro de la edición independiente en Andalucía}

El sector de la industria editorial independiente en Andalucía ha crecido exponencialmente en el siglo xxı. Del total de nuestra muestra, solo el 18,4 \% de editoriales — 14 de las 76 que han respondido a la encuesta - tienen más de dos décadas de supervivencia: dos editoriales se crearon en los años 70 (sevillanas), cuatro en los años 80 (una cordobesa, una granadina, una malagueña y una sevillana), y ocho en los años 90 (dos almerienses, una cordobesa, dos granadinas, una jienense, una malagueña y una sevillana). El 81,6\% restante, 62 editoriales, han nacido a partir del año 2000, y el $60,5 \%$ del total de independientes encuestadas, 46 sellos, después de la crisis económica de 2008. En Málaga, siete nuevas editoriales (de las diez que han participado en nuestra encuesta, el $70 \%$ ) aparecieron después de la crisis económica. En Jaén, tres editoriales independientes son «poscrisis» $(42,9 \%)$, y en Almería, cuatro de siete encuestadas (57,1\%). En el caso de Sevilla son 19 de 24 (79,17\%); en Granada, nueve de 17 (52,9\%); en Cádiz, las seis consultadas (100\%); mientras que en Córdoba son cuatro de cinco (80\%). Observamos, además, que salieron a la luz 13 nuevas editoriales en Andalucía en 2013 (17,1\%) y ocho en 2015 (10,5 \%). En Sevilla nacieron cinco editoriales en 2013, dos en Cádiz, dos en Granada, dos en Málaga, una en Almería y una en Jaén. En Granada surgieron cuatro nuevos sellos en 2014, uno en Córdoba, uno en Jaén y uno en Sevilla, mientras que en 2015, nacieron tres en Málaga y en Sevilla y uno en Almería y Granada, respectivamente. En consecuencia, los dos grandes años de las editoriales independientes andaluzas en activo han sido 2013 y 2015, por lo que concluimos que el sector ha recibido un fuerte impulso en el último lustro, como consecuencia de la crisis económica que no ha afectado a la industria, sino todo lo contrario: ha cobrado fuerza como modelo de emprendimiento.

Además, existen iniciativas que contribuyen a esta sostenibilidad de la industria del libro en nuestra Comunidad como son la Asociación de Editores de Andalucía (AEA), que agrupa — según datos aportados por esta asociación ${ }^{9}$ — alrededor del 85 \% de la facturación de la producción editorial en nuestra Comunidad; 0 el Festival EDITA celebrado en Punta Umbría (Huelva), donde cada año — y desde 1994 — se dan encuentro editores y edi- toriales independientes de diferentes partes del mundo para dar a conocer su trabajo y exponer nuevas fórmulas de distribución y circulación de sus publicaciones $^{10}$

Por otro lado, se observa a nivel nacional que ante la expansión de este perfil editorial «independiente» se han incrementado las pequeñas empresas de edición ${ }^{11}$, frente al retroceso del número de editoriales medianas y grandes.

\section{Tabla 9. Editoriales nacionales agrupadas por tamaño (2015-2016)}

$\begin{array}{llllll} & \mathbf{2 0 1 5} & & \mathbf{2 0 1 6} & & \text { Variación } \\ & \mathbf{N .}{ }^{{ }^{0}} & \mathbf{\%} & \mathbf{N .}^{{ }^{\circ}} & \mathbf{\%} & \mathbf{2 0 1 5 / 2 0 1 6} \\ \text { Editoriales grandes } & 118 & 4 & 112 & 3,7 & -5,1 \\ \text { Editoriales medianas } & 435 & 14,7 & 418 & 13,8 & -3,9 \\ \text { Editoriales pequeñas } & 2.410 & 81,3 & 2.496 & 82,5 & 3,6 \\ \text { Total } & 2.953 & 100 & 3.026 & 100 & 2,1\end{array}$

Fuente: MECD. Panorámica de la edición española de libros 2016.

Según los datos de la Panorámica de la Edición (2016) —los últimos recabados por el Ministerio de Educación, Cultura y Deporte-, con respecto a 2015, en 2016 las editoriales pequeñas han aumentado su presencia en el sector un 3,6 \% más, pasando de 2.410 editoriales en 2015 a 2.496 en 2016. Asimismo, Andalucía (9,3\%) ocupa el tercer lugar —-tras Madrid $(37,5 \%)$ y Cataluña $(28,4 \%)$ - en producción de libros, alcanzando en 2016 los 5.566 libros publicados por editoriales grandes, medianas y pequeñas.

Estas cifras ponen de manifiesto que aunque es notoria — por su producción - la presencia de editoriales medianas y grandes en España, en Andalucía, como en Madrid y Cataluña, hay una apuesta clara por la edición independiente desde comienzos del siglo xxı como modelo de negocio sostenible, lo que contribuye a la necesaria diversidad de nuestro espacio cultural. En el futuro, a medio plazo, es previsible el aumento de estos sellos — cada vez más especializados en determinadas cuotas de mercado — que con su labor editorial preservan el equilibrio del ecosistema del libro. Por esta razón, la Comunidad Autónoma Andaluza habría de poner en marcha políticas de ayuda al mantenimiento, desarrollo y visibilidad de estas pequeñas editoriales, para estar a la vanguardia de la bibliodiversidad nacional. No cabe duda del preciado valor de las editoriales independientes para la cultura y la economía de nuestra región. 


\section{Bibliografía}

BÉRTOLO, CONSTANTINO (2008):

La cena de los notables. Cáceres: Editorial Periférica.

BOURDIEU, PIERRE (2002):

Las reglas del arte. Génesis y estructura del campo literario. Barcelona: Anagrama.

CÁRCAMO-HUECHANTE, LUIS E.; FERNÁNDEZ BRAVO, ÁLVARO Y LAERA, ALEJANDRA (2007):

El valor de la cultura: arte, literatura y mercado en América Latina. Rosario: Beatriz Viterbo.

\section{COLLEU, GILLES (2008):}

La edición independiente como herramienta protagónica de la bibliodiversidad. Buenos Aires: La Marca Editora.

DIEGO, JOSÉ LUIS DE (DIR.) (2006):

Editores y politicas editoriales en Argentina, 1880-2000. Buenos Aires:

Fondo de Cultura Económica.

DIEGO, JOSÉ LUIS DE (2015):

La otra cara de Jano. Buenos Aires: Ampersand.

DISCEPOLO, THIERRY (2013):

La traición de los editores. Madrid: Trama Editorial.

\section{ESTEBARANZ, ARACELI (2004):}

Andaluzas ayer, hoy y mañana: abriendo caminos. Córdoba: Diputación de Córdoba.

\section{GALLEGO CUIÑAS, ANA Y DESTÉFANIS, LAURA (2014):}

«La edición independiente en español: muestras y propuestas», Ínsula, n. ${ }^{\circ}$ 814.

\section{GALLEGO CUIÑAS, ANA Y MARTÍNEZ, ERIKA (COMP.) (2017):}

A pulmón o sobre cómo editar de forma independiente en español. Granada: Esdrújula Ediciones.

\section{LARRAZ, FERNANDO (2010):}

Una historia transatlántica del libro. Relaciones editoriales entre España y América Latina (1936-1950). Gijón: Ediciones Trea.
LÓPEZ DE ABIADA, JOSÉ MANUEL; NEUSCHÄFER, HANS-JÖRG Y LÓPEZ VERNASOCCHI, AUGUSTA (EDS.) (2001):

Entre el ocio y el negocio: Industria editorial y literatura en la España de los 90. Madrid: Verbum.

MANZONI, CELINA (2001):

«¿Editoriales pequeñas o pequeñas editoriales?» en Revista Iberoamericana, n. ${ }^{0} 197$, pp. 781-793.

\section{MINISTERIO DE EDUCACIÓN, CULTURA Y DEPORTE (2017): \\ Anuario de Estadísticas Culturales.}

\section{MINISTERIO DE EDUCACIÓN, CULTURA Y DEPORTE (2018): \\ El Sector del Libro en España.}

\section{MINISTERIO DE EDUCACIÓN, CULTURA Y DEPORTE (2017):}

Panorámica de la edición Española de libros 2016.

\section{PIZARRO, JERÓNIMO (2012):}

La mediación editorial. Sobre la vida póstuma de lo escrito, Madrid: Iberoamericana.

RIVERA, JORGE B. (2004):

El escritor y la industria cultural. Buenos Aires: Atuel.

RUFFEL, LIONEL (2015):

«Nuevas experiencias editoriales y literaturas contemporáneas», Cuadernos LIRICO, 13, pp. 1-11.

\section{SAPIRO, GISÈLE (2009):}

Les contradictions de la globalisation éditoriale. París: Nouveau Monde Éditions.

\section{SCHIFFRIN, ANDRÉ (2011):}

El dinero y las palabras. La edición sin editores. Barcelona: Ediciones Península.

\section{THOMPSON, JOHN B. (2012):}

Merchants of Culture. The Publishing Business in the Twenty-Firt Century. New York: Plume. 



\section{NÚMEROS PUBLICADOS}

\section{0}

El valor monetario de la salud: estimaciones empíricas

La educación postobligatoria en España y Andalucía

La pobreza dual en Andalucía y España

Jubilación y búsqueda de empleo a edades avanzadas

El carácter social de la política de vivienda en Andalucía. Aspectos jurídicos

El camino del éxito: jóvenes en ocupaciones de prestigio

Mutantes de la narrativa andaluza

Gobernanza multinivel en Europa. Una aproximación desde el caso andaluz

Partidos políticos, niveles de gobierno y crecimiento económico regional

Bilingüismo y Educación. Incidencia de la Red de Centros Bilingües de Andalucía

Marroquíes en Andalucía. Dinámicas migratorias y condiciones de vida

Obstáculos y oportunidades. Análisis de la movilidad social intergeneracional en Andalucía

El vandalismo como fenómeno emergente en las grandes ciudades andaluzas

Transformando la gestión de recursos humanos en las administraciones públicas

Valores y conductas medioambientales en España

¿Sabemos elegir? Introducción al estudio de la conducta económica de las personas

Metro ligero e innovación para la movilidad sostenible de las áreas metropolitanas andaluzas

El papel de las regiones en la actual Unión Europea

Nuevos enfoques en el diseño de los copagos farmacéuticos

La inmigración en Andalucía. Un análisis con datos de la Seguridad Social (2007-2008)

Arte contemporáneo y sociedad en Andalucía

La creación de una nueva realidad empresarial. El caso de Andalucía

Nuevos modelos de familia en Andalucía y políticas públicas

Rasgos básicos del envejecimiento demográfico y las personas mayores en Andalucía

Género, salud y orden social. El caso del modelo clínico de transexualidad

Gestión del pluralismo religioso en el ámbito autonómico y local

La educación como factor determinante de la movilidad intergeneracional en Andalucía
Las compañías de bajo coste en los aeropuertos andaluces La construcción del sujeto político entre los jóvenes en riesgo

9: La disposición a pagar por el medio ambiente. Un análisis con datos de Andalucía

La inmigración en Andalucía. Un análisis con datos de la Seguridad Social en 2009

31: Percepción de la desigualdad y demanda de políticas redistributivas en Andalucía

Las violencias masculinas y la prevención de la violencia contra las mujeres

62: Las violencias masculinas y la prevención de la violencia contra las mujeres

La población infantil ante las nuevas tecnologías de la información. Una aproximación a la realidad de los nativos digitales andaluces

El contacto de la ciudadanía con los ayuntamientos como forma de participación política en Andalucía

Hacia un modelo de movilidad urbana sostenible

Las transiciones hacia el empleo de la juventud andaluza

El sector de los alimentos ecológicos en Andalucía: diagnóstico. retos y estrategias

Percepción de los españoles y andaluces ante la pobreza

La presencia de las mujeres en los ayuntamientos andaluces (1979-2011)

70: Un relato sobre identidad y vida buena en Andalucía

Bienestar, desigualdad y pobreza en Andalucía: un estudio comparativo con el resto de España a partir de las encuestas de condiciones de vida 2006 y 2012

Competencias autonómicas y gestión de la cuenca del Guadalquivir

Reformas legislativas, incumplimientos de la Carta Social Europea y su invocación en los órganos judiciales

Reforma constitucional y nuevo paradigma del Estado social. De la ordenación contingente a la organización consciente del bienestar

Bullying, cyberbullying y dating violence. Estudio de la gestión de la vida social en estudiantes de Primaria y Secundaria de Andalucía

¿Odiamos la política?

Determinantes sociales de la salud en Andalucía

Líderes políticos y calendario electoral. Un análisis de la percepción de la población andaluza

La Renta Mínima de Inserción en Andalucía. Alcance y limitaciones

La edición independiente en Andalucía 


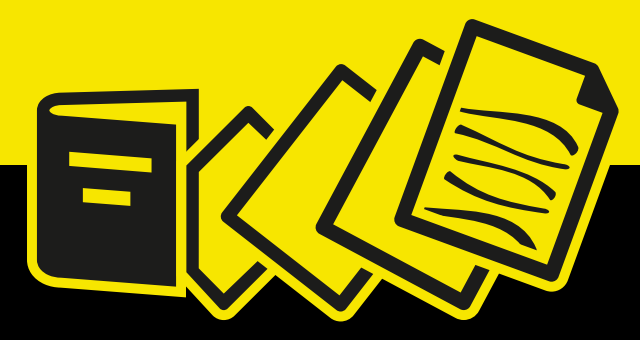

Centro de Estudios Andaluces

CONSEJERÍA DE LA PRESIDENCIA,

ADMINISTRACIÓN LOCAL Y MEMORIA DEMOCRÁTICA 